\title{
ARTICLE
}

\section{Translating the atypical dopamine uptake inhibitor hypothesis toward therapeutics for treatment of psychostimulant use disorders}

Amy Hauck Newman (iD), Jianjing Cao ${ }^{1}$, Jacqueline D. Keighron ${ }^{1}$, Chloe J. Jordan (D) ${ }^{1}$, Guo-Hua Bi ${ }^{1}$, Ying Liang (iD), Ara M. Abramyan ${ }^{1}$, Alicia J. Avelar ${ }^{2}$, Christopher W. Tschumi ${ }^{2,3}$, Michael J. Beckstead ${ }^{2,3}$, Lei Shi ${ }^{1}$, Gianluigi Tanda (D) ${ }^{1}$ and Zheng-Xiong Xi (iD ${ }^{1}$

Medication-assisted treatments are unavailable to patients with cocaine use disorders. Efforts to develop potential pharmacotherapies have led to the identification of a promising lead molecule, JJC8-091, that demonstrates a novel binding mode at the dopamine transporter (DAT). Here, JJC8-091 and a structural analogue, JJC8-088, were extensively and comparatively assessed to elucidate neurochemical correlates to their divergent behavioral profiles. Despite sharing significant structural similarity, JJC8-088 was more cocaine-like, increasing extracellular DA concentrations in the nucleus accumbens shell (NAS) efficaciously and more potently than JJC8-091. In contrast, JJC8-091 was not self-administered and was effective in blocking cocaine-induced reinstatement to drug seeking. Electrophysiology experiments confirmed that JJC8-091 was more effective than JJC8-088 at inhibiting cocaine-mediated enhancement of DA neurotransmission. Further, when VTA DA neurons in DAT-cre mice were optically stimulated, JJC8-088 produced a significant leftward shift in the stimulation-response curve, similar to cocaine, while JJC8-091 shifted the curve downward, suggesting attenuation of DA-mediated brain reward. Computational models predicted that JJC8-088 binds in an outward facing conformation of DAT, similar to cocaine. Conversely, JJC8-091 steers DAT towards a more occluded conformation. Collectively, these data reveal the underlying molecular mechanism at DAT that may be leveraged to rationally optimize leads for the treatment of cocaine use disorders, with JJC8-091 representing a compelling candidate for development.

Neuropsychopharmacology (2019) 44:1435-1444; https://doi.org/10.1038/s41386-019-0366-z

\section{INTRODUCTION}

The opioid crisis in the United States has inspired efforts to improve access to treatment and the development of novel therapeutic strategies has received increased attention and research support $[1,2]$. Nevertheless, abuse and addiction to other illicit drugs, such as cocaine, continues to plague our society and communities with deadly consequences, and for the psychostimulants, no FDA-approved medications are available. Indeed, although opioid-related deaths have been on the rise in the past decade, cocaine-related deaths have also continued to rise, some associated with co-administration of the highly potent opioid fentanyl [3]. Although many FDA-approved drugs have been evaluated in either preclinical and/or clinical studies for the treatment of cocaine or methamphetamine use disorders, none has proven globally effective $[4,5]$. Although reanalysis of some clinical data suggest that subpopulations of patients may benefit from treatment with modafinil $[6,7]$, the discovery of novel therapeutics is required to achieve a broader scope of effectiveness in reducing relapse, with the goal of achieving abstinence.

Modafinil acts as a dopamine (DA) uptake blocker, but does not exhibit cocaine-like abuse potential [8]. We hypothesized that modafinil blocks dopamine transporter (DAT) with a different mechanism from that of cocaine and with lower affinity [9].
Chemical modifications of the modafinil molecule were thus made to improve its affinity for the DAT and further investigate our hypothesis [10-12]. Indeed, binding assays with a Y156F mutant of the human DAT (hDAT) suggested two lead modafinil derivatives, JJC8-088 and JJC8-091, that bind with higher affinity but in different binding modes to cocaine at DAT (Fig. S1). Thus, based on previous studies with analogues of benztropine [13], we posited that these modafinil analogs might yield a new class of atypical DAT inhibitors that do not exhibit cocaine-like behavioral profiles $[9,14]$. We also tested GBR 12909 , a potent and selective DAT inhibitor, as a comparator to further characterize these novel modafinil analogs. Metabolic and pharmacokinetic data [15] further supported their therapeutic potential for the treatment of cocaine use disorders.

\section{MATERIALS AND METHODS}

All experimental procedures were conducted in accordance with the Guide for the Care and Use of Laboratory Animals, National Academy of Sciences, and were approved by the Animal Care and Use Committee of the National Institute on Drug Abuse of the US National Institutes of Health. Additional experimental details can be found in S.I.

\footnotetext{
${ }^{1}$ Molecular Targets and Medications Discovery Branch, National Institute on Drug Abuse, Intramural Research Program, National Institutes of Health, 333 Cassell Drive, Baltimore, MD 21224, USA; ${ }^{2}$ Department of Cellular and Integrative Physiology, UT Health Science Center, San Antonio, TX, USA and ${ }^{3}$ Aging \& Metabolism Research Group, Oklahoma Medical Research Foundation, Oklahoma City, OK, USA

Correspondence: Amy Hauck Newman (anewman@intra.nida.nih.gov)
}

Received: 21 December 2018 Revised: 27 February 2019 Accepted: 27 February 2019

Published online: 11 March 2019 


\section{Drugs}

JJC8-088 (1-(4-(2-((Bis(4-fluorophenyl)methyl)sulfinyl)ethyl)piperazin-1-yl)-3-phenylpropan-2-ol oxalate) and JJC8-091 (1-(4-(2-((Bis (4-fluorophenyl)methyl)sulfinyl)ethyl)piperazin-1-yl)propan-2-ol oxalate) were synthesized as previously reported [10]. Cocaine $\mathrm{HCl}$ and GBR12909 were provided by NIDA IRP.

Intravenous drug self-administration in rats

Male Long-Evans rats (Charles River, Raleigh, NC, USA) were housed individually in a climate-controlled room on a reverse light-dark cycle with ad libitum access to food and water. Intravenous catheterization surgery and cocaine selfadministration procedures under both fixed-ratio (FR) and progressive-ratio (PR) reinforcement schedules have been described previously [16]. After stable cocaine self-administration was achieved as defined in the SI Materials and methods, the effects of JJC8-088 or JJC8-091 on cocaine $(0.5 \mathrm{mg} / \mathrm{kg} /$ infusion) self-administration under FR2 or PR were evaluated. This dose of cocaine is located in the middle of the descending limb of the selfadministration dose-response curve $[17,18]$, which is important for evaluating whether a test compound produces an enhancement or inhibition of cocaine's action. Additional groups were used to evaluate the reinforcing efficacy of JJC8-088 or JJC8-091 alone in drug-naive rats or in rats with a cocaine selfadministration history. Between-subjects designs were used to study the dose effects of JJC8-088 or JJC8-091 on cocaine selfadministration under FR2 or PR reinforcement (for all experiments shown in Fig. 1).

Reinstatement of drug-seeking behavior in rats

Following cocaine self-administration under an FR2 schedule, animals continued cocaine self-administration until stable intake was achieved. Then, the animals underwent extinction training, during which cocaine was replaced by saline and the light and sound cues that previously accompanied cocaine infusions were turned off. After drug-seeking behavior was extinguisheddefined as $\leq 10$ active lever presses during each $3 \mathrm{~h}$ session for at least 3 consecutive days - the animals were divided into four groups to observe the effects of JJC8-088, GBR12909, or JJC8-091 either alone on reinstatement or with cocaine $(10 \mathrm{mg} / \mathrm{kg}$, i.p.) on pretreatment-induced reinstatement of drug-seeking behavior. This cocaine dose was chosen because $10 \mathrm{mg} / \mathrm{kg}$ cocaine priming produces robust reinstatement responding without significant unwanted side-effects such as sedation, locomotor impairment or seizures in rats after extinction $[16,17,19,20]$. A between-subjects design was used to study the dose effects of JJC8-088, GBR 12909, or JJC8-091 on reinstatement responses by themselves or on cocaine-induced reinstatement of drug-seeking behavior (for all experiments shown in Fig. 2).

Optical brain-stimulation reward in mice

For optical brain-stimulation reward experiments, DAT-cre mice were injected with AAV5-EF1a-DIO-ChR2-EGFP or the control virus (AAV2-EF1a-DIO-EGFP) and implanted with bilateral custom-made optical fibers targeted to the ventral tegmental area (VTA). Behavioral training and drug testing occurred in mouse operant chambers (Med Associates) interfaced with optogenetic stimulation equipment.

\section{In vivo microdialysis in rats}

Microdialysis procedures have been extensively described previously [21-23]. Briefly, concentric dialysis probes were implanted in the nucleus accumbens shell (NAS) of rats; $24 \mathrm{~h}$ after probe implantation, Ringer's solution was infused at $1 \mu \mathrm{l} / \mathrm{min}$ through the probes. After 2-4 consecutive pretreatment samples, the subjects were injected i.p. with saline or a test compound. DA was detected with high-performance liquid chromatography coupled to electrochemical detection.
Fast-scan cyclic voltammetry (FSCV) in rats

Surgical and FSCV procedures were previously reported [24, 25]. Briefly, rats were maintained under urethane anesthesia and placed in a stereotaxic frame during the entire experimental session. The skull was exposed, and holes were drilled for electrode placements, with atlas coordinates identical to [24]. NAS DA was identified and measured using a UEI potentiostat and breakout box running Tarheel-CV (University of North Carolina, Chapel Hill electronics shop).

Patch clamp electrophysiology in mouse brain slices Whole cell patch clamp recordings were conducted as described previously [26]. Briefly, male DBA/2J mice aged 7-13 weeks were sacrificed, and horizontal midbrain slices $(200 \mu \mathrm{m})$ containing the substantia nigra were cut with a vibrating microtome. DA neurons were identified by location, appearance, and electrophysiological properties, and were voltage clamped at $-55 \mathrm{mV}$. DAT inhibitors were applied by bath perfusion.

Computational studies

Methods are described in S.I.

\section{RESULTS}

JJC8-088 and JJC8-091 show divergent effects on cocaine selfadministration in rats

To determine whether the novel DAT inhibitors JJC8-088 and JJC8-091 alter drug-taking behavior, we compared the effects of both compounds on intravenous (i.v.) cocaine selfadministration under an FR2 schedule of reinforcement. JJC8$088(3,10,30 \mathrm{mg} / \mathrm{kg}$, i.p., $30 \mathrm{~min}$ prior to testing) significantly decreased the number of cocaine infusions in a dose-dependent manner (Fig. 1a). In contrast, JJC8-091 (10, 30, $56 \mathrm{mg} / \mathrm{kg}$ ) failed to significantly alter cocaine self-administration (Fig. 1b). Neither JJC8-088 nor JJC8-091 altered inactive lever responses at any of the doses tested (Fig. 1a, b, right panels). Of note, compounds that are either cocaine-like or block the effects of cocaine can produce a similar reduction in cocaine self-administration under low FR (FR1, FR2) reinforcement by reinforcer substitution [18] or attenuated drug reward [27], respectively. Therefore, we further evaluated the effects of these two compounds on break-point for cocaine self-administration under a PR schedule of reinforcement, an index of drug reinforcing strength and/or motivation to seek drug [28]. We found that JJC8-088 $(10,30 \mathrm{mg} / \mathrm{kg}$, i.p.) failed to significantly alter the break-point (Fig. 1c), while JJC8091, at the same doses $(10,30 \mathrm{mg} / \mathrm{kg}$, i.p.), was effective in decreasing the break-point for cocaine self-administration (Fig. 1c). These data suggest that pretreatment with JJC8-091, but not JJC8-088, significantly decreases cocaine's reinforcing effects and reduces motivation to seek drug under these conditions.

JJC8-091, in contrast to JJC8-088, does not substitute for cocaine in rats

To examine whether JJC8-088 or JJC8-091 itself was reinforcing, two groups of rats were initially trained to self-administer cocaine. After stable self-administration was achieved, cocaine was replaced by either JJC8-088 or JJC8-091. When cocaine was replaced by JJC8-088 (initially $0.5 \mathrm{mg} / \mathrm{kg} /$ infusion, followed by 1.0 $\mathrm{mg} / \mathrm{kg} /$ infusion) in one group of rats, JJC8-088 substitution maintained significant and stable self-administration in a dosedependent manner relative to the active lever responses either before JJC8-088 substitution or after JJC8-091 substitution (Fig. 1d). In contrast, JJC8-091 substitution failed to maintain stable selfadministration and instead, gradually produced extinction of behavior. This extinction was similar to that previously observed with substitution of saline [19] or an earlier generation modafinil analogue and atypical DAT inhibitor, JJC8-016 [20]. These findings 
A

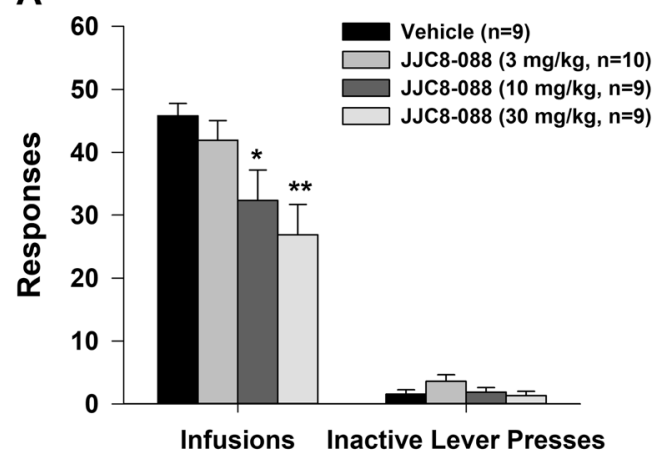

C

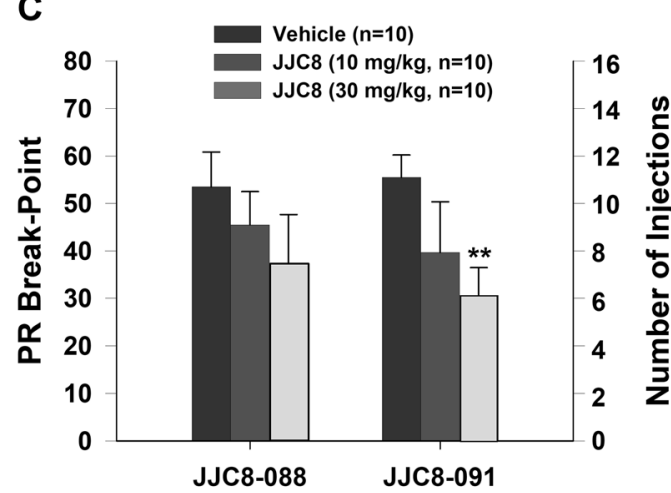

E

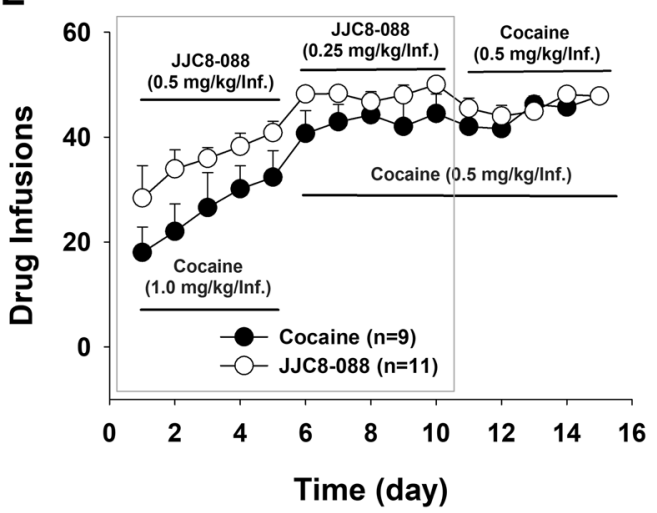

B

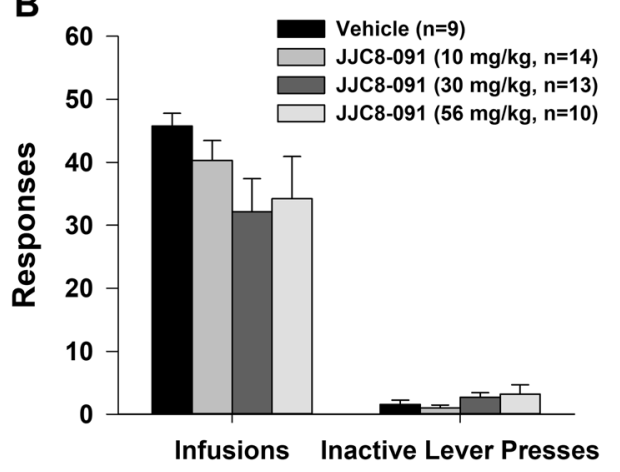

D Drug Switch

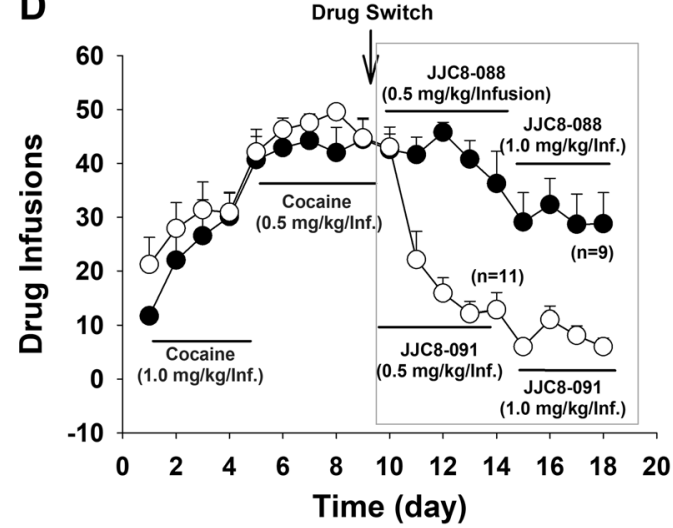

$\mathbf{F}$

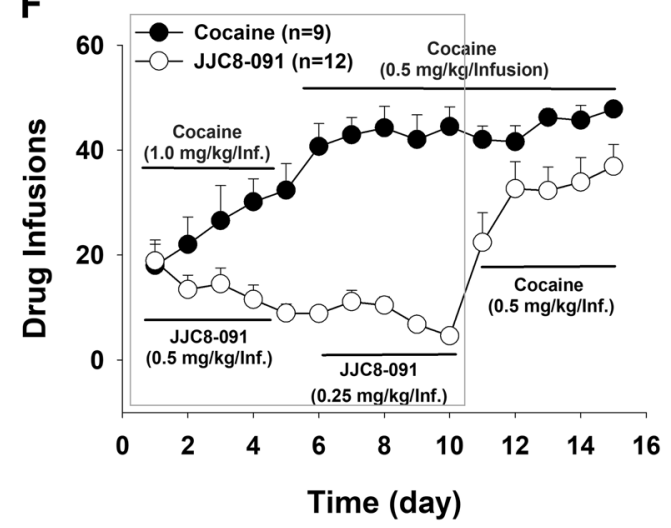

Fig. 1 Evaluation of the effects of JJC8-088 and JJC8-091 on cocaine self-administration or self-administration by themselves. a JJC8-088 (3, 10, $30 \mathrm{mg} / \mathrm{kg}$, i.p.) dose-dependently decreased cocaine self-administration under FR2 reinforcement conditions $\left(F_{3,33}=5.59, P<0.01\right.$, one-way ANOVA). Post hoc individual group comparisons illustrated that JJC8-088 significantly decreased cocaine infusions after $10 \mathrm{mg} / \mathrm{kg}(q=3.65$, $P<0.05)$ or $30 \mathrm{mg} / \mathrm{kg}(q=5.12, P<0.01)$. b JJC8-091 $(10,30,56 \mathrm{mg} / \mathrm{kg}$, i.p.) did not produce a significant reduction in cocaine selfadministration under FR2 reinforcement $\left(F_{3,42}=1.67 ; P>0.05\right)$. c JJC8-091, but not JJC8-088, significantly lowered the number of cocaine injections (and also break-point for cocaine self-administration) under the PR reinforcement schedule (left panel, $F_{2,27}=0.78 ; P>0.05 ;$ right panel, $F_{2,27}=4.28 ; P<0.05$, one-way ANOVA). Post hoc individual group comparisons revealed a significant reduction in cocaine selfadministration after $10 \mathrm{mg} / \mathrm{kg}(q=3.143, P<0.05)$ or $30 \mathrm{mg} / \mathrm{kg} \mathrm{JJC8-091}$ treatment $(q=4.855, P<0.01)$, when compared to the vehicle control group; d JJC8-088, but not JJC8-091, substitution (initially $0.5 \mathrm{mg} / \mathrm{kg} / \mathrm{infusion}$ for 5 days followed by $1.0 \mathrm{mg} / \mathrm{kg} / \mathrm{infusion}$ for additional 4 days) sustained stable self-administration in rats previously self-administered cocaine. Two-way ANOVA for repeated measures over time (for the data after JJC compound substitution, highlighted in the gray box) revealed a significant drug main effect $\left(F_{1,18}=39.09, P<0.001\right)$, time main effect $\left(F_{8,144}=17.82, P<0.001\right)$ and drug $\times$ time interaction $\left(F_{8,144}=4.69, P<0.001\right)$. e Naive rats self-administered JJC8-088 intravenously similar to cocaine. Two-way ANOVA for repeated measures over time (for the data shown in a gray box) revealed a significant drug main effect $\left(F_{1,18}=5.31, P<0.05\right)$, but did not reveal a significant treatment $\times$ time interaction $\left(F_{9,162}=0.48, P>0.05\right)$. $\mathbf{f}$ Naive rats did not self-administer JJĆ-091 during the initial 10 days of self-administration training. When JJC8-091 was replaced by cocaine, animals rapidly acquired selfadministration behavior for cocaine. Two-way ANOVA for repeated measures over time (for the data shown in a gray box) revealed a significant cocaine vs. JJC8-091 main effect $\left(F_{1,19}=51.56, P<0.001\right)$, time main effect $\left(F_{9,171}=3.93, P<0.001\right)$ and drug $\times$ time interaction $\left(F_{9}, 171=15.03, P<0.001\right) .{ }^{*} P<0.05,{ }^{* * P}<0.01$, compared to vehicle $(\mathbf{a}, \mathbf{c})$, JJC8-088 substitution (d), or cocaine group (f) 

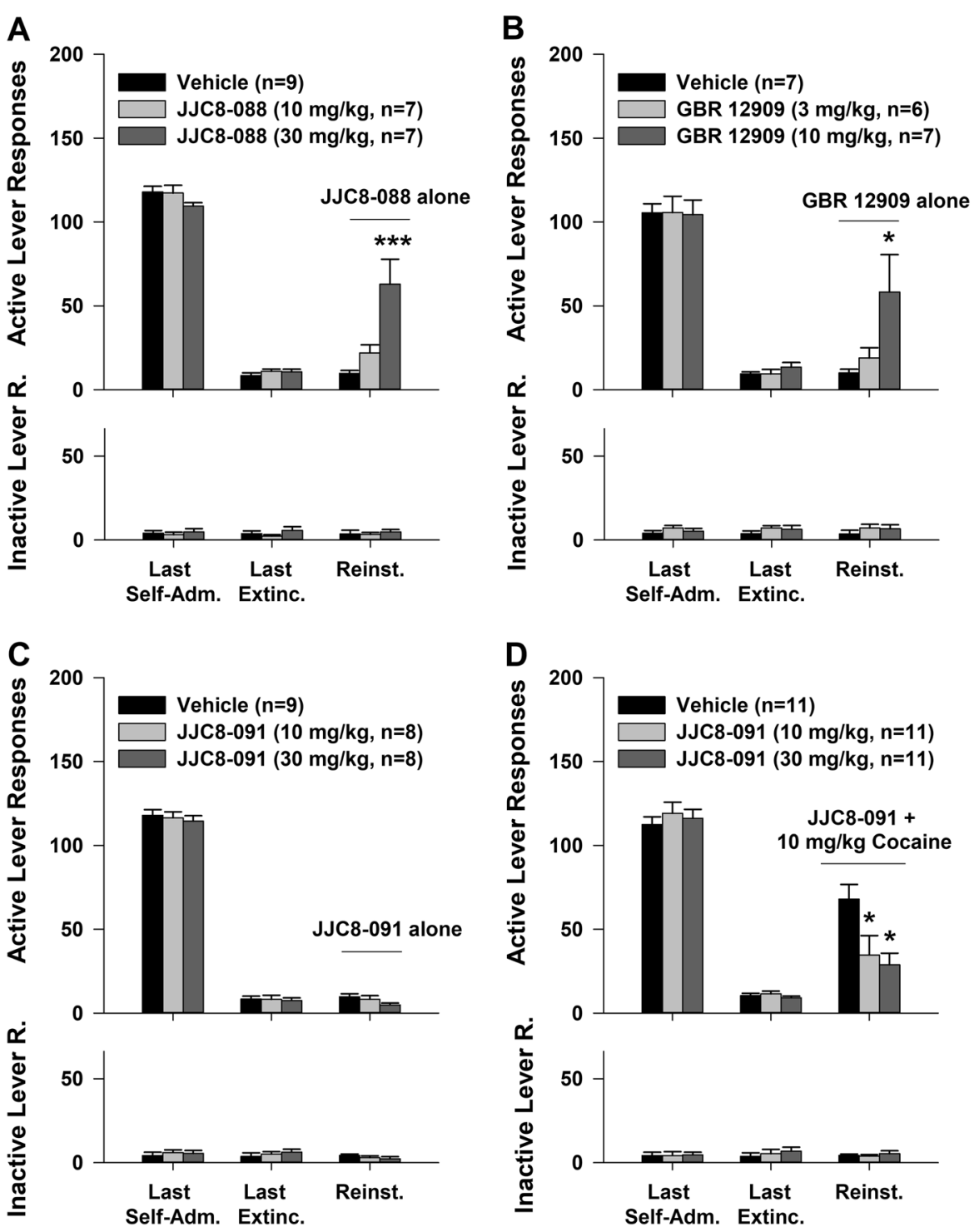

Fig. 2 Effects of JJC8-088, JJC8-091, GBR12909 or cocaine on reinstatement of drug-seeking behavior. a-c Active and inactive lever responses during the last session of cocaine self-administration, last session of extinction, and reinstatement testing, illustrating that systemic administration of JJC8-088 (10, $30 \mathrm{mg} / \mathrm{kg}$, i.p.) $\left(\mathbf{a} F_{2,20}=13.18, P<0.001\right)$ or GBR12909 (3, $10 \mathrm{mg} / \mathrm{kg}$, i.p.) $\left(\mathbf{b} F_{2,17}=4.04, P<0.05\right)$, but not JJC8$091\left(10,30 \mathrm{mg} / \mathrm{kg}\right.$, i.p.) $\left(\mathbf{c} F_{2,22}=2.58, P>0.05\right)$, dose-dependently reinstated drug-seeking behavior as indicated by active lever responses. Post-hoc individual group comparisons revealed a significant reinstatement after $30 \mathrm{mg} / \mathrm{kg} \mathrm{JJC8-088}(\mathbf{a} q=7.08, P<0.001)$ or after $10 \mathrm{mg} / \mathrm{kg}$ GBR12909 (b $q=3.80, P<0.05$ ). d Active and inactive lever responses during the last session of cocaine self-administration, extinction and reinstatement testing, illustrating that pretreatment with JJC8-091 (10,30 mg/kg, i.p.) dose-dependently inhibited cocaine-induced reinstatement of drug-seeking behavior $\left(F_{2,30}=5.78, P<0.01\right)$. Post-hoc individual group comparisons revealed a significant reduction in cocaine-seeking behavior after $10 \mathrm{mg} / \mathrm{kg}(q=3.79, P<0.05)$ or $30 \mathrm{mg} / \mathrm{kg} J \mathrm{JC} 8-091(q=4.46, P<0.05)$ administration. ${ }^{*} P<0.05 ;{ }^{* * *} P<0.001$, compared to the vehicle control

suggest that JJC8-088 is reinforcing and may have cocaine-like abuse liability, while JJC8-091 is not.

JJC8-088 is self-administered in drug naive rats; JJC8-091 is not We next investigated whether naive rats would self-administer JJC8-088 or JJC8-091. Figure 1e shows that two groups of naive rats quickly learned to lever press in order to receive cocaine (initially $1.0 \mathrm{mg} / \mathrm{kg} / \mathrm{infusion}$, followed by $0.5 \mathrm{mg} / \mathrm{kg} / \mathrm{infusion}$ ) or JJC8-088 (initially $0.5 \mathrm{mg} / \mathrm{kg} /$ infusion, followed by $0.25 \mathrm{mg} / \mathrm{kg} /$ infusion). Strikingly, the two groups displayed a similar pattern of drug self-administration. When JJC8-088 was replaced by cocaine, animals displayed a similar level of self-administration (Fig. 1e).

In contrast, another group of naive rats initially paired with JJC8091 (initially $0.5 \mathrm{mg} / \mathrm{kg} /$ infusion, followed by $0.25 \mathrm{mg} / \mathrm{kg} /$ infusion) did not acquire self-administration behavior during the initial 10 consecutive days (Fig. 1f). When JJC8-091 was replaced by cocaine, the rats displayed quick acquisition and stable selfadministration of cocaine (Fig. 1f).

JJC8-088, but not JJC8-091, induces reinstatement of drug seeking in rats

We then examined whether JJC8-088 or JJC8-091 was able to reinstate drug-seeking behavior in rats whose responding was extinguished from previous cocaine self-administration, as observed with cocaine or GBR12909, another DAT inhibitor [29]. Figure 2 shows the total number of active and inactive lever responses observed during the last session of cocaine selfadministration, the last session of extinction, and the reinstatement test session with different drug priming. JJC8-088 priming $(10,30 \mathrm{mg} / \mathrm{kg}$, i.p.) produced a robust and dose-dependent 
reinstatement response (Fig. 2a), similar to GBR12909 (Fig. 2b). In contrast, JJC8-091 priming at doses of 10 and $30 \mathrm{mg} / \mathrm{kg}$ did not evoke reinstatement of drug-seeking behavior (Fig. 2c). Unlike active responses, neither drug priming altered inactive lever responses in each reinstatement test (Fig. 2a-c, lower panels).

JJC8-091 pretreatment inhibits cocaine-induced reinstatement of drug seeking in rats

We next examined whether JJC8-091 might have therapeutic potential in reducing relapse to drug-seeking behavior. A single non-contingent cocaine-priming dose $(10 \mathrm{mg} / \mathrm{kg}$, i.p.) evoked robust reinstatement of cocaine-seeking behavior in rats whose responding was extinguished from previous cocaine selfadministration. Pretreatment with JJC8-091 (10, $30 \mathrm{mg} / \mathrm{kg})$ significantly attenuated cocaine-triggered reinstatement of drugseeking behavior (Fig. $2 \mathrm{~d}$ ).

JJC8-091 reduces and JJC8-088 enhances optical brain-stimulation reward in mice

To examine whether a DA-dependent mechanism was associated with the effects of each compound, we expressed light-sensitive channelrhodopsin 2 (ChR2) into VTA DA neurons in DAT-cre mice (Fig. 3a, b), then observed optical intracranial self-stimulation (oICSS). Figure $3 c$ shows representative oICSS records (i.e., active lever responses) maintained by descending stimulation light frequencies (10 min at each frequency) during daily $60 \mathrm{~min}$ sessions. Figure 3d, e shows mean rate-frequency function curves, illustrating typical sigmoidal-shape curves under vehicle treatment conditions in DAT-cre mice. Pretreatment with JJC8-088 dosedependently shifted this DA-maintained olCSS curve to the left (Fig. 3d) suggesting that JJC8-088 produces an enhancement in olCSS, similar to cocaine [30]. In contrast, pretreatment with JJC8091 dose-dependently shifted the rate-frequency function curve downward suggesting a significant reduction in DA-dependent oICSS behavior.

JJC8-088 and JJC8-091 differentially increase extracellular NAS DA levels in rats and reduce DA clearance

Both compounds were evaluated for their effects on extracellular DA in the NAS using in vivo microdialysis. Previous microdialysis studies have shown that a drug's ability to increase extracellular DA levels may relate to its reinforcing effects and potential for abuse [22, 31, 32].

Baseline DA values averaged $55.6 \pm 4.0$ fmoles/sample $(n=31)$ and did not differ between experimental groups (One-way ANOVA, $F_{5,25}=0.770, P=0.58$ ). Systemic administration of JJC8$088(1,3$, and $10 \mathrm{mg} / \mathrm{kg})$ produced a significant, dose-dependent increase in dialysate DA levels from the NAS (Fig. 4a). The lowest dose was not effective, while higher doses significantly increased DA levels. The maximal increase in DA levels $(\sim 100 \%$ and $300 \%$ above baseline for 3 and $10 \mathrm{mg} / \mathrm{kg}$, respectively) was obtained at $\sim 30 \mathrm{~min}$ after administration (Fig. 4a), and was long lasting, with values still $\sim 100 \%$ above baseline $3 \mathrm{~h}$ after injection (Fig. 4a).

Similarly, administration of JJC8-091 (10, 32, and $56 \mathrm{mg} / \mathrm{kg}$ i.p.) dose-dependently increased extracellular NAS DA levels (Fig. 4b).
A

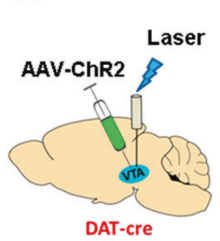

B

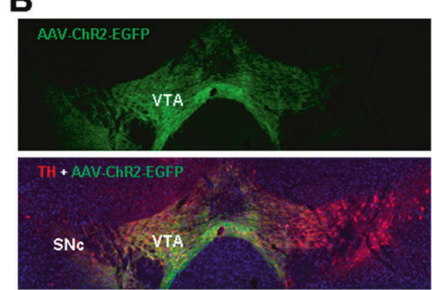

C

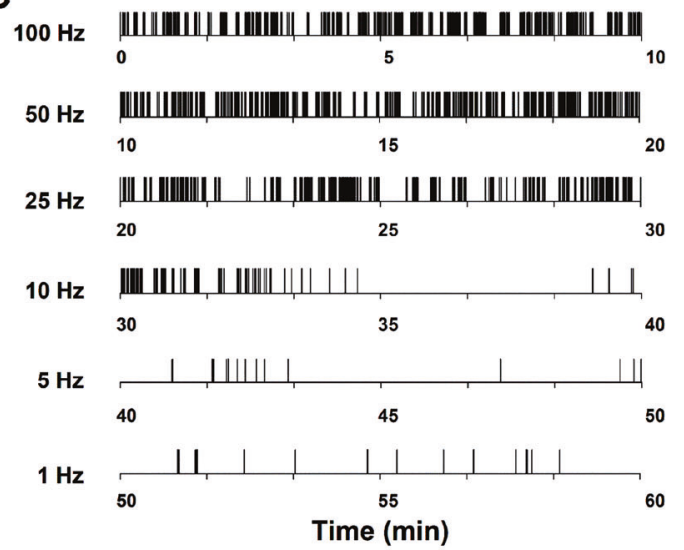

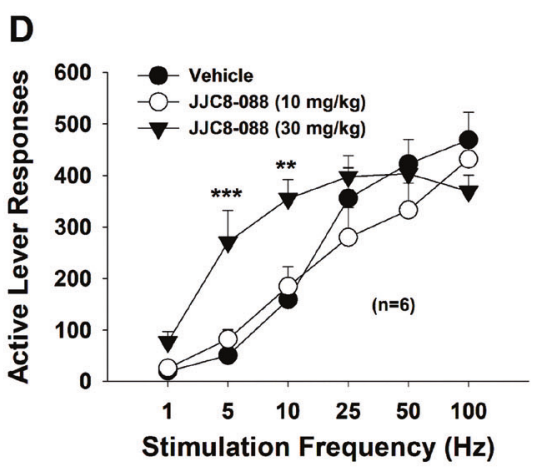

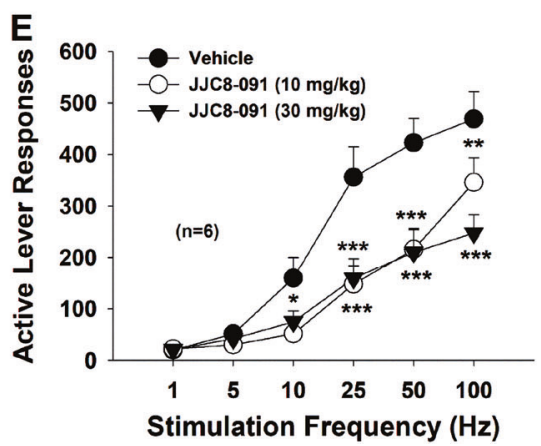

Fig. 3 Evaluation of the rewarding effects of JJC8-088 and JJC8-091 in optical brain-stimulation reward (or optical intracranial self-stimulation, oICSS) in rats. a Schematic diagrams illustrating the target brain region (VTA) of the AAV-ChR2-GFP microinjection and intracranial optical fiber implantation (left). b Representative images of AAV-ChR2-EGFP expression (green) and tyrosine hydroxylase (TH)-staining (red) in the VTA. c Representative olCSS records in a single session from a single mouse under descending stimulation frequency (from high to low, 10 min per frequency), indicating that photoactivation of VTA dopaminergic neurons in DAT-Cre mice induced robust olCSS behavior (lever presses) in a stimulation frequency-dependent manner. $\mathbf{d}$ Systemic administration of JJC8-088 dose-dependently shifted the stimulation-response curve to the left, indicating enhanced brain-stimulation reward. Two-way ANOVAs for repeated measures over drug dose and stimulation frequency revealed drug treatment main effect $\left(F_{2,15}=2.67, P<0.05\right)$, frequency main effect $\left(F_{5,75}=108.01, P<0.001\right)$, and treatment $X$ frequency interaction $\left(F_{10,75}=6.94, P<0.001\right)$. e Systemic administration of JJC8-091 shifted the stimulation-response curve downward. Two-way ANOVAs for repeated measures over drug dose and stimulation frequency revealed a drug treatment main effect $\left(F_{2,15}=7.96, P<0.01\right)$, frequency main effect $\left(F_{5,75}=112.35, P<0.001\right)$, and treatment $X$ frequency interaction $\left(F_{10.75}=6.84, P<0.001\right)$. ${ }^{*} P<0.05 ;{ }^{* *} P<0.01,{ }^{* * *} P<$ 0.001 compared to the vehicle control group 

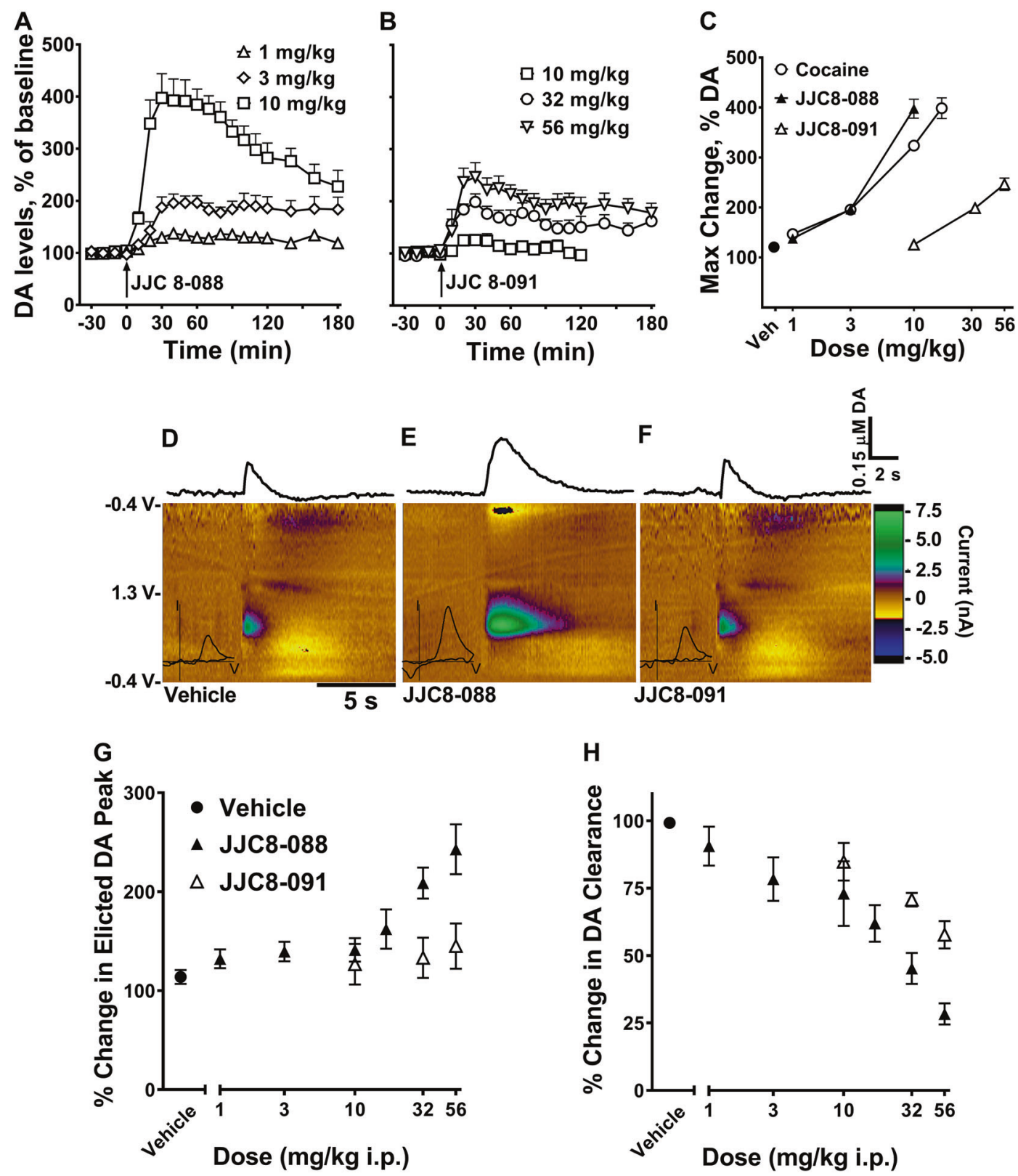

Fig. 4 Evaluation of the effects of JJC8-088 and JJC8-091 on extracellular DA in NAS. a-c, microdialysis experiments. Time course of effects of administration of JJC8-088 (1, 3, and $10 \mathrm{mg} / \mathrm{kg}$ i.p., $n=5,6$, and 6, respectively, panel a) and JJC8-091 $(10,32$, and $56 \mathrm{mg} / \mathrm{kg}$ i.p., $n=4,5$, and 5, respectively, panel b) on extracellular DA in dialysates from NAS. A two-way ANOVA for repeated measures over time indicated main effects of dose $\left(\mathbf{a} F_{2,14}=46.77, P<0.01 ; \mathbf{b} F_{2,11}=8.14, P<0.01\right)$, time $\left(\mathbf{a} F_{15,210}=14.26, P<0.01 ; \mathbf{b} F_{15,165}=12.32, P<0.01\right)$, and their interaction (a $F_{30,210}=5.75, P<0.01$; b $F_{30,165}=2.39, P<0.01$ ). Results are means $\pm \mathrm{SEM}$, of the amount of DA in 10-min dialysate samples, expressed as percentage of baseline values, uncorrected for probe recovery. c shows the maximum increase in extracellular DA levels in the NAS in rats obtained following administration of JJC8-088 (1,3, and $10 \mathrm{mg} / \mathrm{kg}$ i.p.) or JJC8-091 (10, 32, and $56 \mathrm{mg} / \mathrm{kg}$ i.p.). For comparison, previous microdialysis data on cocaine (1-17 mg/kg i.p.) effects on DA levels in the NAS obtained under identical experimental conditions are shown [22]. $\mathbf{d}-\mathbf{h}, \mathrm{FSCV}$ experiments. $\mathbf{d}-\mathbf{f}$ are representative colorplots with corresponding cyclic voltammetry (inset) and concentration plots (above) for vehicle (10\% DMSO, 15\% Tween 80, d), JJC8-088 (32 mg/kg, e) and JJC8-091 (32 mg/kg, f) showing the effects of each compound on the stimulus-elicited DA peak $\left(\mathrm{DA}_{\mathrm{Max}}\right)$ and clearance time from the electrode. $\mathbf{g}-\mathbf{h}$ represent cumulative dosing effects of JJC8-088 (1-56 mg/kg,

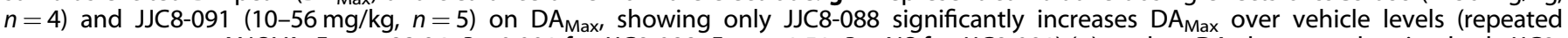
measures, one-way ANOVA, $F_{6,18}=23.94, P<0.001$ for JJC8-088; $F_{3,12}=1.51, P=$ NS for JJC8-091) (g), and on DA clearance showing both JJC8088 (repeated measures, one-way ANOVA, $F_{6,18}=23.34, P<0.001$ ) and JJC8-091 (repeated measures, one way ANOVA, $F_{3,12}=13.01, P<0.001$ ) decrease DA clearance as compared to baseline (h). JJC8-088 reduced DA clearance more effectively than JJC8-091 (repeated measures, twoway ANOVA, main effect drug, $F_{1,7}=14.2, P<0.01$; main effect dose, $F_{3,21}=39.49, P<0.01$; drug by dose interaction, $F_{3,21}=3.14, P<0.05$ ). Results are presented as means \pm SEM and are expressed as a percentage of initial baseline values

Only the higher doses ( 32 and $56 \mathrm{mg} / \mathrm{kg}$ ) elicited a significant stimulation in DA levels with a maximal increase $(\sim 100 \%$ and $150 \%$ above baseline for 32 and $56 \mathrm{mg} / \mathrm{kg}$, respectively) obtained after $30 \mathrm{~min}$ (Fig. 4b), and a long-lasting effect ( $60-70 \%$ increase
$3 \mathrm{~h}$ after injection). However, a comparison of the present results with previous cocaine microdialysis data [22] shows that the maximal change in DA levels elicited by cocaine (1-17 mg/kg i.p.) is very similar to that elicited by JJC8-088, in contrast to JJC8-091 
(Fig. 4c). Moreover, JJC8-088 was more potent and more efficacious in increasing DA levels compared to JJC8-091 (Fig. 4c).

While microdialysis is a useful indicator of potential changes in DA neurotransmission [33], FSCV was performed to evaluate the effects of both compounds on both the stimulation of DA release $\left(D A_{M a x}\right)$ and the rate of DA clearance from the extracellular space [34]. In Figure $4 d-f$ representative color plots of stimulated DA release after administration of vehicle, JJC8-088, or JJC8-091 are depicted. The vehicle did not significantly modify $\mathrm{DA}_{\text {Max }}$ (Fig. 4g). Cumulative doses of JJC8-088 produced a significant increase in $\mathrm{DA}_{\text {Max }}$ (Fig. 4g), while JJC8-091 was ineffective at all doses tested. Both JJC8-088 and JJC8-091 dose dependently reduced the rate of
DA clearance (Fig. 4h), but JJC8-088 was more effective than JJC8091.

JJC8-091, but not JJC8-088, blocks cocaine-induced enhancement of $\mathrm{D} 2$ receptor currents

We next tested the effects of the compounds on D2 receptormediated potassium currents, which we previously showed are enhanced by cocaine $[26,35,36]$. We used electrophysiological recordings of substantia nigra DA neurons in brain slices from mice to study the effects of cocaine, JJC8-088, and JJC8-091 on currents elicited by DA iontophoresis. For these experiments we chose concentrations of JJC8-088 and JJC8-091 that were $~ 10-30$

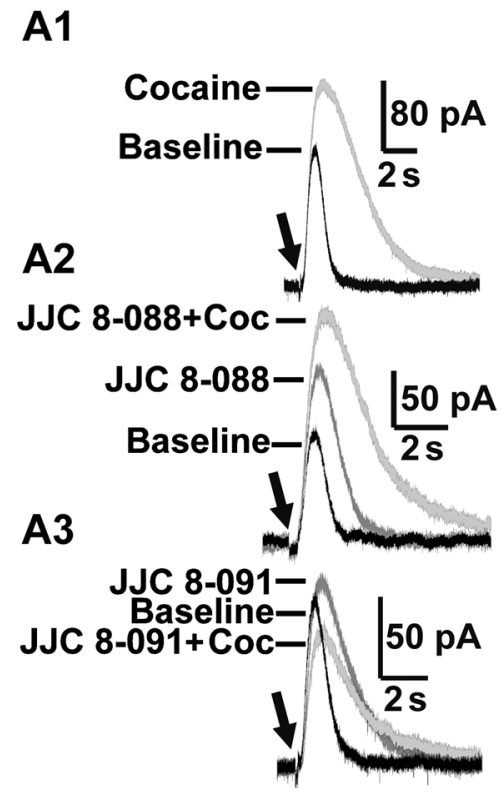

B

C

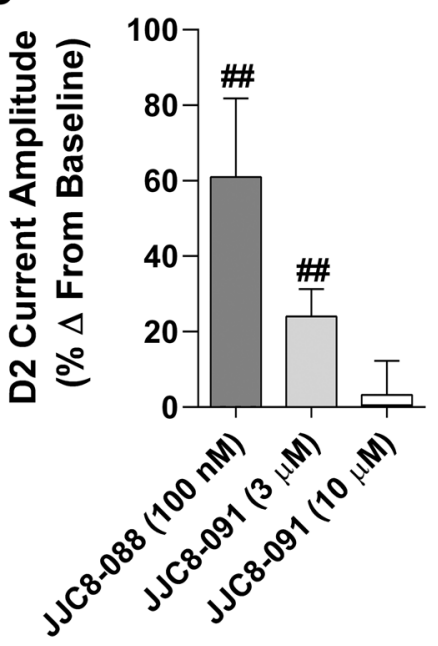

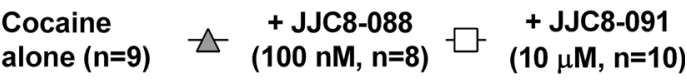

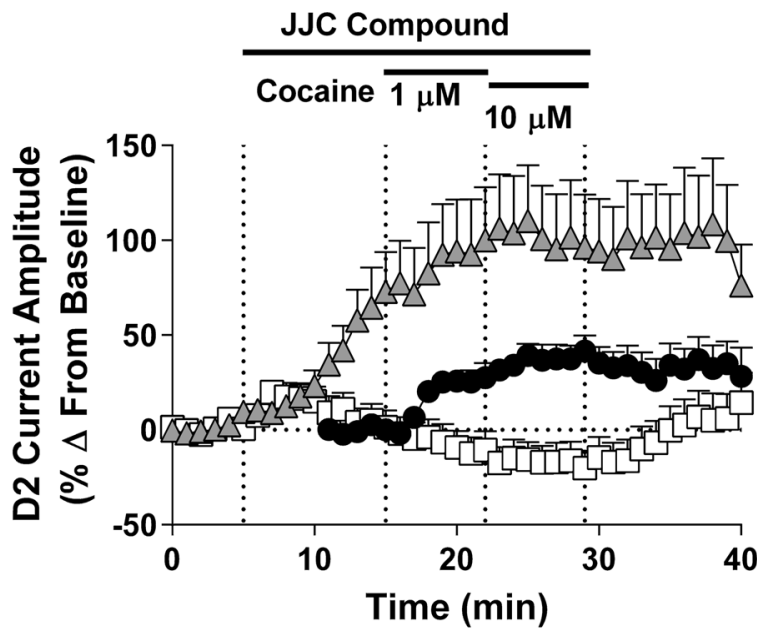

D

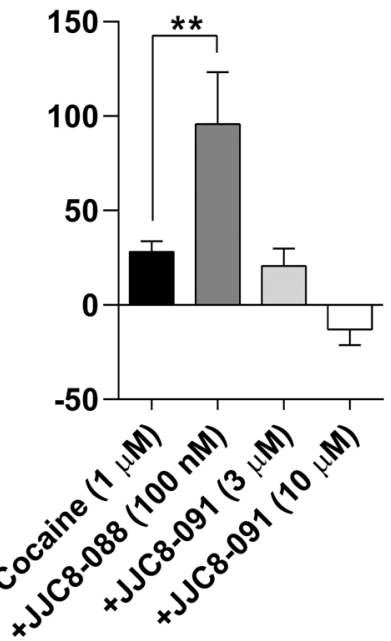

E

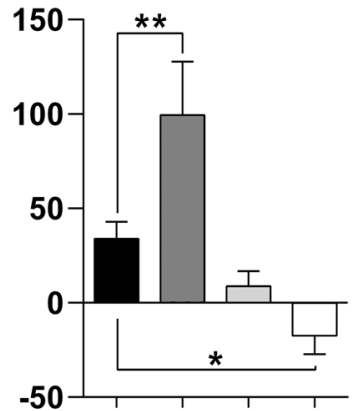

Fig. 5 JJC8-091 prevents cocaine-induced enhancement of currents elicited by DA iontophoresis. Representative traces from experiments where D2 receptor-mediated currents (D2 currents) were elicited via iontophoresis in the presence of a1 cocaine, a2 JJC8-088 followed by cocaine, or a3 JJC8-091 followed by cocaine. Arrows indicate iontophoretic ejection of DA. b Cocaine-induced enhancement of D2 currents was blocked by pre-incubation with JJC8-091 $(10 \mu \mathrm{M})$ or additively increased by pre-incubation with JJC8-088 (100 nM). c Summary data from

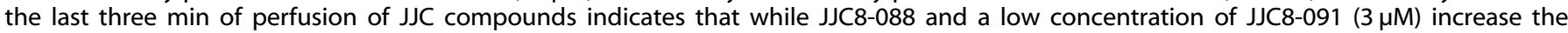
amplitude of D2 currents, there is no effect of a high concentration of JJC8-091 (10 $\mu \mathrm{M})$. d Summary data from the last three min of perfusion of a low concentration of cocaine $(1 \mu \mathrm{M})$ alone or in the presence of JJC compounds indicates that JJC8-088 enhances, while JJC8-091 does not affect, low-concentration cocaine-induced enhancement of D2 currents $\left(F_{3,31}=9.87, P<0.001\right)$. e Summary data from the last three min of perfusion of a high concentration of cocaine $(10 \mu \mathrm{M})$ indicate that JJC8-088 has an additive effect, while JJC8-091 (10 $\mu \mathrm{M})$ prevents, highconcentration cocaine-induced enhancement of $D 2$ currents $\left(F_{3,31}=10.61, P<0.001\right)$. " Represents difference compared to within-cell baseline (paired $t$-test), ${ }^{\#} P<0.05,{ }^{\# \#} P<0.01 ;{ }^{*}$ represents difference compared to cocaine alone (Holm-Sidak multiple comparisons), ${ }^{*} P<0.05,{ }^{* *} P<0.01$ 
times the affinity of the compounds for DAT [10]. We observed that either JJC8-088 or JJC8-091 modestly enhanced DA current amplitudes (Fig. 5a-c). However, these compounds differed greatly in the degree to which they modified the cellular effects of cocaine. JJC8-088 appeared to be additive with cocaine's effects (Fig. 5b) while JJC8-091 completely blocked cocaine-induced enhancement of DA currents (Fig. 5d, e). Surprisingly, coapplication of JJC8-091 and cocaine reduced the amplitude of DA currents (Fig. 5e). These results suggest that JJC8-091 is more effective than JJC8-088 at inhibiting cocaine's effects on DA signaling, an observation that was also evident when currents were evoked by stimulated release of endogenous DA (Fig. S2).

Molecular modeling predicts different binding modes of JJC8-091 and JJC8-088 at DAT

Based on our previous mechanistic findings [9, 11, 37, 38], we went on to characterize the binding modes of JJC8-091 and JJC8088 in the central ligand binding (S1) site of hDAT, by conducting molecular dynamics (MD) simulations (Fig. S3). Our simulation results showed that both the hydroxyl group and the protonated $\mathrm{N}$ of JJC8-088 form interactions with Asp79, whereas only the hydroxyl group of JJC8-091 interacts with Asp79 (Fig. 6a, b). These different strengths of interactions with Asp79 are congruent with the experimental binding affinity of JJC8-088 being significantly higher ( 116 fold) than that of JJC8-091 [10]. Importantly, our results showed that the terminal phenyl moiety in JJC8-088 contributes to locking the transporter in an outward-open conformation whereas the absence of this moiety enables JJC8091 to induce hDAT to transition to a more inward-facing conformation.

To further characterize this observation, we quantified differences of structural elements between the hDAT/JJC8-091 and hDAT/JJC8-088 complexes, by applying the previously described pairwise interaction analyzer for DAT (PIA-DAT) [39]. Specifically, our analysis showed that the side chain phenyl group of Phe320 rotates to a "closed" conformation in the presence of JJC8-091, but not JJC8-088, making hydrophobic interactions with the propanol moiety of JJC8-091 (Fig. 6a, b). In coordination with this change,

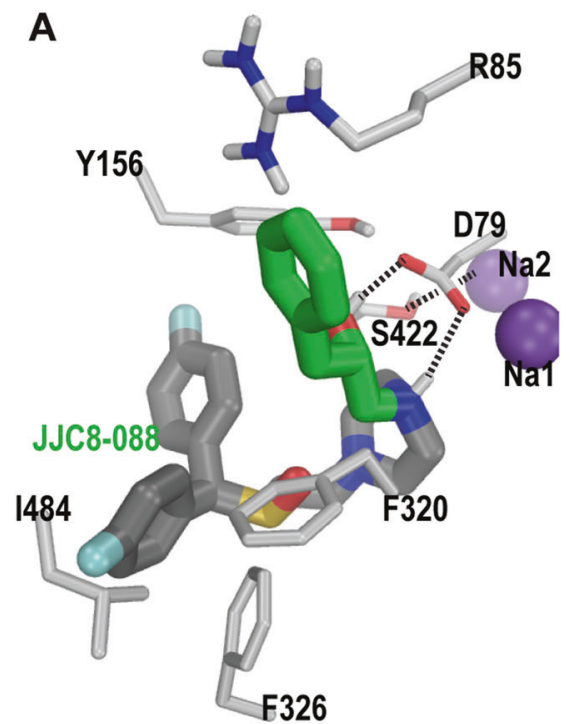

B

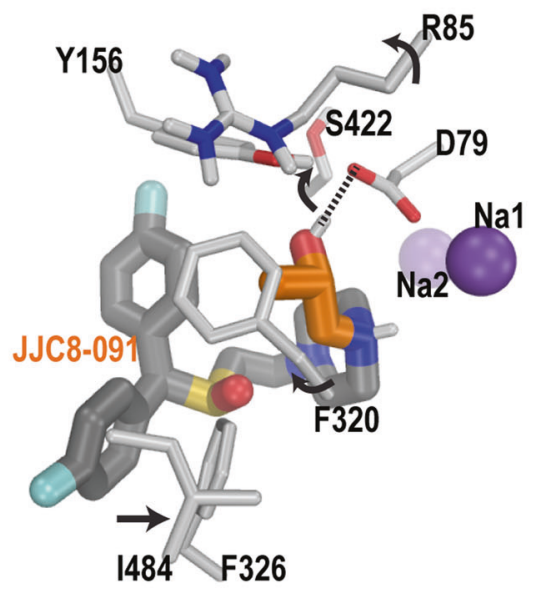

C

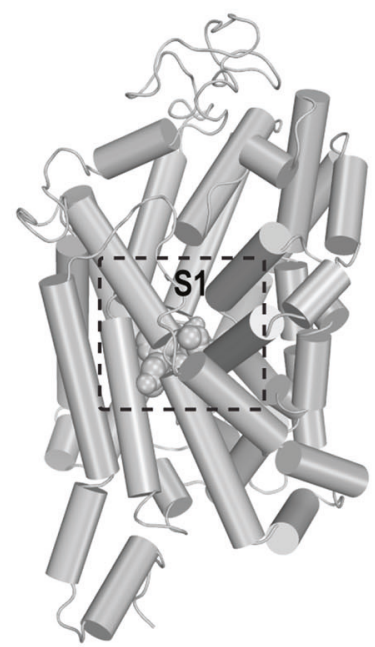

D

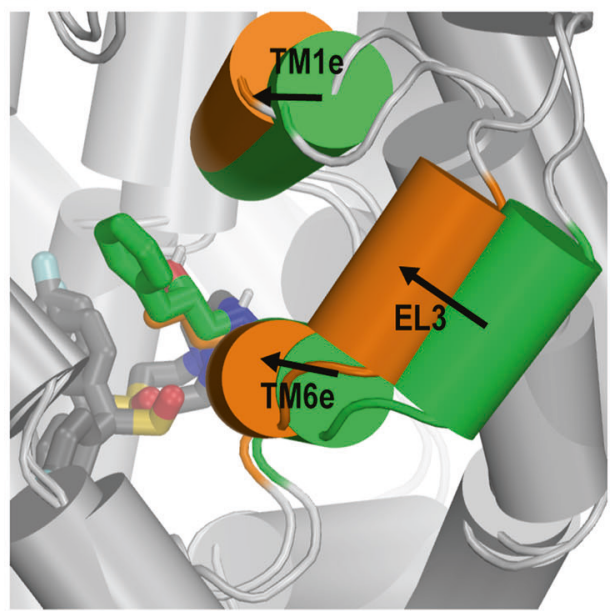

Fig. 6 Binding of JJC8-091 steers the hDAT towards an inward-facing conformation, compared to that of JJC-088. $\mathbf{a}$, $\mathbf{b}$ The binding modes of JJC8-088 and JJC8-091 in the S1 site of hDAT. The rearrangements of S1-residues (shown by black arrows) induced by the binding of JJC8-091 prepare the transporter to transition towards more inward-facing conformation: the S1-gating residue Phe320 goes to its "closed" conformation, while the coordination between Ser422 and Na2 is disrupted. The interactions formed between the ligands and Asp79, and between Ser422 and Na2, are indicated by black dotted lines. c The equilibrated hDAT/JJC8-091complex viewed parallel to the membrane normal, with the S1 site indicated by a dotted box. d The superimposition of the equilibrated hDAT/JJC8-088 and hDAT/JJC8-091 complexes shows the inward movements of TM1e, TM6e, and EL3 in hDAT/JJC8-091 (orange) compared to hDAT/JJC8-088 (green) 
Arg85 moves downward and makes a cation- $\pi$ interaction with Phe320, while lle484 rearranges to maintain its interaction with Phe320 (Fig. 6a, b; Fig. S3B,C). In addition, a Na2 coordinating residue, Ser422, loses its coordination with Na2 in hDAT/JJC8-091 (Fig. 6a, b; Fig. S3D). These changes are characteristic features of the transporter transitioning to an inward-facing conformation [39-41].

At the subsegment level, we found that the distances among extracellular subsegments in hDAT/JJC8-091 are smaller than those in hDAT/JJC8-088 (upper left box in Fig. S3D), indicating a more outward-occluded conformation of hDAT in the presence of JJC8-091. In particular, the relatively large inward rearrangements of TM1e, TM6e, and EL3 in the presence of JJC8-091 are shown in Fig. $6 c$, d. On the intracellular side, we observed that the distances among the subsegments in hDAT/JJC8-091 are larger compared to those in hDAT/JJC8-088 (lower right box in Fig. S3D), indicating that JJC8-091 steers the hDAT conformation to be more inwardfacing.

\section{DISCUSSION}

Herein we describe two structurally similar DAT inhibitors, only differing in the absence (JJC8-091) or presence (JJC8-088) of a terminal phenyl group, with divergent behavioral profiles in rodents. We previously discovered that both compounds have high Y156F/WT DAT binding affinity ratios, an indication that these compounds bind differently to DAT than cocaine, which inspired us to evaluate them further in models of cocaine abuse [10]. Interestingly, in our rodent models, JJC8-088 demonstrates a robust cocaine-like behavioral profile, supporting selfadministration as well as inducing reinstatement to cocaine seeking behavior, like another DAT inhibitor, GBR12909. In contrast, JJC8-091 does not produce cocaine-like behaviors in any of these models. Moreover, JJC8-091 pretreatment attenuates motivation to self-administer cocaine and reduces cocaineinduced reinstatement to drug-seeking behaviors. These results complement previous studies wherein JJC8-091 showed a more promising profile than JJC8-088 in both short access and especially long-access methamphetamine self-administration models [15].

Neurochemical and electrophysiological studies show cocainelike increases in NAS DA levels for JJC8-088 and a significantly lower response to JJC8-091. JJC8-088 elicits a large and rapid increase in extracellular DA levels as revealed by the time course of its effects, which resembles the DA-stimulating actions of DAT blockers that maintain self-administration behavior in rats. In contrast, the time course of JJC8-091 effects shows its limited ability to stimulate DA levels, as compared to JJC8-088. These data suggest that the rapid stimulation of NAS DA levels obtained by JJC8-088 administration may be consistent with potential for abuse, as evidenced by its ability to function as a reinforcer. The slow, limited, and long-lasting effects of JJC8-091 on extracellular DA are consistent with the behavioral data showing its inability to maintain self-administration behavior. These data are commensurate with previous reports on DAT inhibitors with atypical or unique pharmacological profiles, like JHW007 or modafinil $[9,22$, 42-46].

These results also correlate with data obtained by optical stimulation of VTA DA neurons wherein JJC8-088 produces a leftward shift in the olCSS stimulation-response curve, similar to cocaine, while JJC8-091 shifts the curve downward, suggesting attenuation in brain reward function. FSCV studies show both compounds inhibit DA uptake, as indicated by significant reductions in DA clearance rates, where JJC8-088 produces effects greater in magnitude than JJC8-091. Also, JJC8-088, but not JJC8091, produced significant cocaine-like effects on stimulus-elicited DA $_{\text {Max }}$ further suggesting a potential atypical profile for JJC8-091. Further, blockade of cocaine's enhancement of DA-mediated currents in DA neurons by JJC8-091 is consistent with our previous findings with similar compounds [26]. We previously showed that the benztropine analogue, JHW007, had little effect on its own but was able to blunt the cocaine-induced increase in DA currents, while R-modafinil alone enhanced DA currents and interacted in an additive manner with cocaine [26]. Similar findings were obtained here for JJC8-088, which appeared more cocaine-like, and JJC8-091, which dose-dependently inhibited the acute enhancement produced by cocaine in an even more efficacious manner than JHW007. Strikingly, cocaine decreased the amplitude of DA currents following pre-incubation with $10 \mu \mathrm{M}$ JJC8-091, suggesting elimination of its effects on DA uptake and/or recruitment of a distinct mechanism to decrease D2 receptor signaling. Taken together, our findings suggest that inhibition of the initial rise in DA signaling during the first few minutes of cocaine exposure could be a strong cellular predictor of behavioral action of atypical DAT inhibitors.

Collectively, these data support JJC8-091 as a development candidate for the treatment of cocaine use disorders. Moreover, the MD simulation studies show that the terminal phenyl ring of JJC8-088 interacts with the residues on the extracellular side of the S1 site, and stabilizes the transporter in an outward-open conformation. The absence of such a moiety in JJC8-091 results in occlusion of the S1 site and release of the Na2, two features indicating that the transporter is transitioning toward an inwardfacing conformation, a trend similarly induced by the bound atypical DAT inhibitor JHW007 [39]. Thus, while JJC8-088 is cocaine-like on all measures in this report and binds to DAT in an outward-open conformation, JJC8-091 binds to a more occluded conformation, which is sufficient to prevent cocaine from binding to DAT and eliciting its reinforcing effects. The computational data support our hypothesis that binding mode at DAT confers different behavioral profiles in structurally similar DAT inhibitors. We suspect that the different conformational states affect how DAT interacts with its intracellular scaffolding proteins and/or its propensity to be internalized, which would eventually result in different downstream functional consequences, such as cell firing. Thus, of the two analogues described in this report, only JJC8-091 is an atypical DAT inhibitor and is currently being developed as a medication for the treatment of psychostimulant use disorders, a fundamental and unmet public heath need.

\section{FUNDING AND DISCLOSURE}

Funding was provided by the NIDA-IRP Z1A DA 000389, DA000611, DA000606, NIH grant R01 DA032701 and funds from the Presbyterian Health Foundation. We thank Mark Coggiano, Juliana Quarterman and Apre Dixon-Gleaves for technical assistance. $\mathrm{AHN}$ and JJC are inventors on the licensed US patent E-073-2013/0-US-06 NIH0072US2 in which JJC8-088 and JJC8-091 are disclosed. The NIH owns all rights to this patent. All other authors declare that they have no conflict of interest.

\section{AUTHOR CONTRIBUTIONS}

$A H N, M J B, L S, G T$, and $Z X X$ designed the experiments. CJJ, G-HB, and YL performed the behavioral experiments. AHN and JC synthesized JJC8-088 and JJC8-091. JDK and GT performed the microdialysis and voltammetry experiments. AMA and LS performed the computational studies. AJA, CWT, and MJB performed the electrophysiological experiments. AHN wrote the manuscript. MJB, LS, GT, and ZXX revised the manuscript.

\section{ADDITIONAL INFORMATION}

Supplementary Information accompanies this paper at (https://doi.org/10.1038/ s41386-019-0366-z)

Publisher's note: Springer Nature remains neutral with regard to jurisdictional claims in published maps and institutional affiliations. 


\section{REFERENCES}

1. Johnson K, Jones C, Compton W, Baldwin G, Fan J, Mermin J, et al. Federal response to the opioid crisis. Curr HIV/AIDS Rep. 2018;15:293-301.

2. Volkow ND, Collins FS. The role of science in addressing the opioid crisis. N Engl J Med. 2017;377:391-4.

3. Khatri UG, Viner K, Perrone J. Lethal fentanyl and cocaine intoxication. N Engl J Med. 2018;379:1782.

4. Czoty PW, Stoops WW, Rush CR. Evaluation of the "Pipeline" for development of medications for cocaine use disorder: a review of translational preclinical, human laboratory, and clinical trial research. Pharmacol Rev. 2016;68:533-62.

5. Ballester J, Valentine G, Sofuoglu M. Pharmacological treatments for methamphetamine addiction: current status and future directions. Expert Rev Clin Pharmacol. 2017;10:305-14.

6. Kampman KM, Lynch KG, Pettinati HM, Spratt K, Wierzbicki MR, Dackis C, et al. A double blind, placebo controlled trial of modafinil for the treatment of cocaine dependence without co-morbid alcohol dependence. Drug Alcohol Depend. 2015;155:105-10.

7. Anderson AL, Li SH, Biswas K, McSherry F, Holmes T, Iturriaga E, et al. Modafinil for the treatment of methamphetamine dependence. Drug Alcohol Depend. 2012;120:135-41.

8. Mereu M, Bonci A, Newman AH, Tanda G. The neurobiology of modafinil as an enhancer of cognitive performance and a potential treatment for substance use disorders. Psychopharmacology. 2013:229:415-34.

9. Loland CJ, Mereu M, Okunola OM, Cao J, Prisinzano TE, Mazier S, et al. R-modafinil (armodafinil): a unique dopamine uptake inhibitor and potential medication for psychostimulant abuse. Biol Psychiatry. 2012;72:405-13.

10. Cao J, Slack RD, Bakare OM, Burzynski C, Rais R, Slusher BS, et al. Novel and high affinity 2-[(diphenylmethyl)sulfinyl]acetamide (modafinil) analogues as atypical dopamine transporter inhibitors. J Med Chem. 2016;59:10676-91.

11. Okunola-Bakare OM, Cao J, Kopajtic T, Katz JL, Loland CJ, Shi L, et al. Elucidation of structural elements for selectivity across monoamine transporters: novel 2[(diphenylmethyl)sulfinyl]acetamide (modafinil) analogues. J Med Chem. 2014;57:1000-13.

12. Cao J, Prisinzano TE, Okunola OM, Kopajtic T, Shook M, Katz JL, et al. Structureactivity relationships at the monoamine transporters for a novel series of modafinil (2-[(diphenylmethyl)sulfinyl]acetamide) analogues. ACS Med Chem Lett. 2010;2:48-52.

13. Tanda G, Newman AH, Katz JL. Discovery of drugs to treat cocaine dependence: behavioral and neurochemical effects of atypical dopamine transport inhibitors. Adv Pharmacol. 2009b;57:253-89.

14. Loland CJ, Desai RI, Zou MF, Cao J, Grundt P, Gerstbrein K, et al. Relationship between conformational changes in the dopamine transporter and cocaine-like subjective effects of uptake inhibitors. Mol Pharmacol. 2008;73:813-23.

15. Tunstall BJ, Ho CP, Cao J, Vendruscolo JCM, Schmeichel BE, Slack RD, et al. Atypical dopamine transporter inhibitors attenuate compulsive-like methamphetamine self-administration in rats. Neuropharmacology. 2018;131:96-103.

16. Li X, Peng XQ, Jordan CJ, Li J, Bi GH, He Y, et al. mGluR5 antagonism inhibits cocaine reinforcement and relapse by elevation of extracellular glutamate in the nucleus accumbens via a CB1 receptor mechanism. Sci Rep. 2018;8:3686.

17. Keck TM, John WS, Czoty PW, Nader MA, Newman AH. Identifying medication targets for psychostimulant addiction: unraveling the dopamine D3 receptor hypothesis. J Med Chem. 2015;58:5361-80.

18. Xi ZX, Song R, Li X, Lu GY, Peng XQ, He Y, et al. CTDP-32476: a promising agonist therapy for treatment of cocaine addiction. Neuropsychopharmacology. 2017;42:682-94

19. Xi ZX, Newman AH, Gilbert JG, Pak AC, Peng XQ, Ashby CR Jr., et al. The novel dopamine D3 receptor antagonist NGB 2904 inhibits cocaine's rewarding effects and cocaine-induced reinstatement of drug-seeking behavior in rats. Neuropsychopharmacology. 2006;31:1393-405.

20. Zhang HY, Bi GH, Yang HJ, He Y, Xue G, Cao J, et al. The novel modafinil analog, JJC8-016, as a potential cocaine abuse pharmacotherapeutic. Neuropsychopharmacology. 2017;42:1871-83.

21. Garces-Ramirez L, Green JL, Hiranita T, Kopajtic TA, Mereu M, Thomas AM, et al. Sigma receptor agonists: receptor binding and effects on mesolimbic dopamine neurotransmission assessed by microdialysis. Biol Psychiatry. 2011;69:208-17.

22. Kohut SJ, Hiranita T, Hong SK, Ebbs AL, Tronci V, Green J, et al. Preference for distinct functional conformations of the dopamine transporter alters the relationship between subjective effects of cocaine and stimulation of mesolimbic dopamine. Biol Psychiatry. 2014;76:802-9.

23. Tanda G, Pontieri FE, Di Chiara G. Cannabinoid and heroin activation of mesolimbic dopamine transmission by a common mu1 opioid receptor mechanism. Science. 1997a;276:2048-50.

24. Keighron JD, Giancola JB, Shaffer RJ, DeMarco EM, Coggiano MA, Slack RD, et al. (2018). Distinct effects of (R)-modafinil and its (R)- and (S)-fluoro-analogs on mesolimbic extracellular dopamine assessed by voltammetry and microdialysis in rats. Eur J Neurosci. https://doi.org/10.1111/ejn.14256

25. Ramsson ES, Howard CD, Covey DP, Garris PA. High doses of amphetamine augment, rather than disrupt, exocytotic dopamine release in the dorsal and ventral striatum of the anesthetized rat. J Neurochem. 2011;119:1162-72.

26. Avelar AJ, Cao J, Newman AH, Beckstead MJ. Atypical dopamine transporter inhibitors R-modafinil and JHW 007 differentially affect D2 autoreceptor neurotransmission and the firing rate of midbrain dopamine neurons. Neuropharmacology. 2017;123:410-9.

27. Song R, Bi GH, Zhang HY, Yang RF, Gardner EL, Li J, et al. Blockade of D3 receptors by YQA14 inhibits cocaine's rewarding effects and relapse to drug-seeking behavior in rats. Neuropharmacology. 2014;77:398-405.

28. Richardson NR, Roberts DC. Progressive ratio schedules in drug selfadministration studies in rats: a method to evaluate reinforcing efficacy. J Neurosci Methods. 1996;66:1-11.

29. Van Der Zee P, Koger HS, Gootjes J, Hespe W. Aryl 1,4-dialk(en)ylpiperazines as selective and very potent inhibitors of dopamine uptake. Eur J Med Chem.1980;15:363-70.

30. Han X, He Y, Bi GH, Zhang HY, Song R, Liu QR, et al. CB1 receptor activation on VgluT2-expressing glutamatergic neurons underlies delta(9)-tetrahydrocannabinol (delta(9)-thc)-induced aversive effects in mice. Sci Rep. 2017;7:12315

31. Pontieri FE, Tanda G, Di Chiara G. Intravenous cocaine, morphine, and amphetamine preferentially increase extracellular dopamine in the "shell" as compared with the "core" of the rat nucleus accumbens. Proc Natl Acad Sci USA. 1995;92:12304-8.

32. Tanda G, Pontieri FE, Frau R, Di Chiara G. Contribution of blockade of the noradrenaline carrier to the increase of extracellular dopamine in the rat prefrontal cortex by amphetamine and cocaine. Eur J Neurosci. 1997b;9:2077-85.

33. Miele $M$, Boutelle MG, Fillenz $M$. The source of physiologically stimulated glutamate efflux from the striatum of conscious rats. J Physiol. 1996;497:745-51.

34. Budygin EA, Kilpatrick MR, Gainetdinov RR, Wightman RM. Correlation between behavior and extracellular dopamine levels in rat striatum: comparison of microdialysis and fast-scan cyclic voltammetry. Neurosci Lett. 2000;281:9-12.

35. Beckstead MJ, Grandy DK, Wickman K, Williams JT. Vesicular dopamine release elicits an inhibitory postsynaptic current in midbrain dopamine neurons. Neuron. 2004;42:939-46.

36. Branch SY, Beckstead MJ. Methamphetamine produces bidirectional, concentration-dependent effects on dopamine neuron excitability and dopamine-mediated synaptic currents. J Neurophysiol. 2012;108:802-9.

37. Zou MF, Cao J, Abramyan AM, Kopajtic T, Zanettini C, Guthrie DA, et al. StructureActivity relationship studies on a series of 3alpha-[Bis(4-fluorophenyl)methoxy] tropanes and 3alpha-[Bis(4-fluorophenyl)methylamino]tropanes as novel atypical dopamine transporter (DAT) inhibitors for the treatment of cocaine use disorders. J Med Chem. 2017;60:10172-87.

38. Bisgaard $\mathrm{H}$, Larsen MA, Mazier $\mathrm{S}$, Beuming $\mathrm{T}$, Newman $\mathrm{AH}$, Weinstein $\mathrm{H}$, et al. The binding sites for benztropines and dopamine in the dopamine transporter overlap. Neuropharmacology. 2011;60:182-90.

39. Abramyan AM, Stolzenberg S, Li Z, Loland CJ, Noe F, Shi L. The isomeric preference of an atypical dopamine transporter inhibitor contributes to its selection of the transporter conformation. ACS Chem Neurosci. 2017;8:1735-46.

40. Cheng MH, Kaya C, Bahar I. Quantitative assessment of the energetics of dopamine translocation by human dopamine transporter. J Phys Chem B. 2018;122:5336-46.

41. Razavi AM, Khelashvili G, Weinstein H. A Markov state-based quantitative kinetic model of sodium release from the dopamine transporter. Sci Rep. 2017;7:40076.

42. Hiranita T, Soto PL, Newman AH, Katz JL. Assessment of reinforcing effects of benztropine analogs and their effects on cocaine self-administration in rats: comparisons with monoamine uptake inhibitors. J Pharmacol Exp Ther. 2009;329:677-86.

43. Mereu M, Chun LE, Prisinzano TE, Newman AH, Katz JL, Tanda G. The unique psychostimulant profile of $(+/-)$-modafinil: investigation of behavioral and neurochemical effects in mice. Eur J Neurosci. 2017;45:167-74.

44. Reith ME, Blough BE, Hong WC, Jones KT, Schmitt KC, Baumann MH, et al. Behavioral, biological, and chemical perspectives on atypical agents targeting the dopamine transporter. Drug Alcohol Depend. 2015;147:1-19.

45. Tanda G, Li SM, Mereu M, Thomas AM, Ebbs AL, Chun LE, et al. Relations between stimulation of mesolimbic dopamine and place conditioning in rats produced by cocaine or drugs that are tolerant to dopamine transporter conformational change. Psychopharmacology. 2013;229:307-21.

46. Tanda G, Newman AH, Ebbs AL, Tronci V, Green JL, Tallarida RJ, et al. Combinations of cocaine with other dopamine uptake inhibitors: assessment of additivity. J Pharmacol Exp Ther. 2009a;330:802-9. 